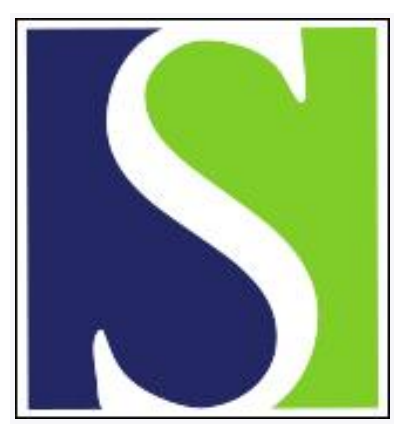

Scand J Work Environ Health 1983;9(2):201-203

https://doi.org/10.5271/sjweh.2425

Issue date: Apr 1983

The protective influence of logger's safety equipment.

by Klen T, Vayrynen ST

This article in PubMed: www.ncbi.nlm.nih.gov/pubmed/6648418

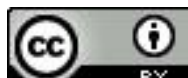

This work is licensed under a Creative Commons Attribution 4.0 International License 


\title{
The protective influence of logger's safety equipment
}

\author{
by Tapio Klen, DSc (Agr \& Forestry), Seppo T Väyrynen, LSc (Eng) ${ }^{\top}$
}

\begin{abstract}
KLEN T, VAYRYNEN S. The protective influence of logger's safety equipment. Scand $j$ work environ health 9 (1983) 201-203. The effects of loggers' personal protectors and the safety equipment of chain saws were investigated with a postal questionnaire. The sample included 1,200 loggers. The main purpose of the inquiry was to collect data on accidents and near-accidents; special attention was paid to the role and behavior of protective devices in both accident and near-accident situations. Twenty-seven percent of the power saw operators reported incidents (near-accidents) which had occurred within the last year and in which some personal protector or piece of safety equipment had prevented harmful mechanical contact. The workers estimated that the average absence from work due to these reported near-accidents would have been 15 workdays if the injury had not been prevented. Sixty percent of the near-accidents occurred during limbing operations, and $30 \%$ during felling. The protective equipment which most often prevented injuries was safety boots, which were followed by the safety helmet and leg protectors. The chain of the saw was stopped by the safety padding of the protective equipment in every other near-accident involving chain saws. The chain was blocked by padding material in every sixth situation. In $10 \%$ of the near-accidents, the chain perforated the protective equipment.
\end{abstract}

Key terms: accidents in forest work, near-accidents in forest work, personal protectors.

For many reasons personal protective equipment plays an important role in forest work. The effects of loggers' personal protectors and the safety equipment of chain saws were investigated with the aid of a postal questionnaire. The sample comprised 1,200 loggers. The response rate was $91 \%$. The main purpose of the inquiry was to collect data on accidents and near-accidents; special attention was paid to the role and behavior of protective devices in both accident and near-accident situations. The data were collected at the beginning of 1980 .

The frequency with which protective equipment was used is shown in table 1 .

1 Kuopio Regional Institute of Occupational Health, Kuopio, Finland.

Reprint reguests to: Dr T Klen, Kuopio Regional Institute of Occupational Health, PO Box 261, SF-70101 Kuopio 10, Finland.

\section{Near-accidents}

Twenty-seven percent of the power saw operators reported incidents (near-accidents) which had occurred within the last year and in which some personal protector or safety equipment had prevented harmful mechanical contact.

Table 1. Frequency of the use of various protective equipment in forest work.

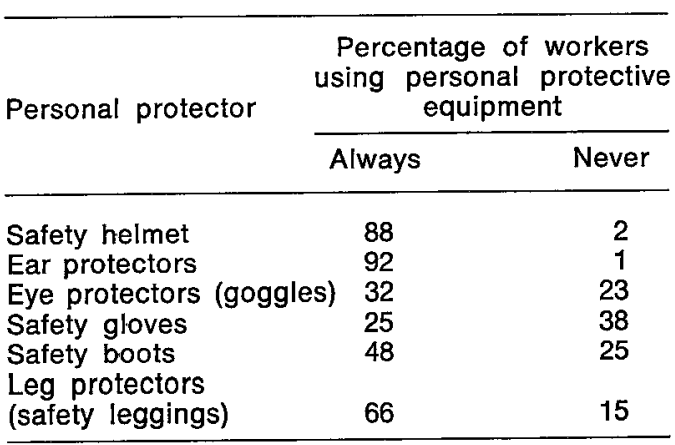


Table 2. Protective equipment which prevented injury in the reported near-accidents.

\begin{tabular}{lcc}
\hline $\begin{array}{l}\text { Personal protector } \\
\text { or safety equipment }\end{array}$ & $\begin{array}{c}\text { Number } \\
\text { of cases }\end{array}$ & $\begin{array}{c}\text { Percentage of } \\
\text { all } \\
\text { preventions }\end{array}$ \\
\hline Safety helmet & 79 & 27 \\
Ear protectors & - & 0 \\
Eye protectors & 8 & 3 \\
Safety gloves & 2 & 1 \\
Safety boots & 111 & 37 \\
Leg protectors & 68 & 23 \\
Front handle guard & 19 & 6 \\
of chain saws & 11 & 4 \\
Chain brake & - & 0 \\
Rear handle guard & - & 0 \\
Throttle control lockout & - & 0 \\
Chain catcher & - & 101 \\
\hline Total & 298 & \\
\hline
\end{tabular}

The workers estimated that the average absence from work due to the near-accidents reported would have been 15 workdays had the accidents not been prevented. Some workers thought that the hazardous incidents could have been fatal. When the average number of days absent was calculated, the maximum number was restricted to 50 . This restriction was made because of the uncertainty of the subjective estimations.

Sixty percent of the near-accidents occurred during limbing operations, and $30 \%$ during felling. The total number of reported incidents was 298 (table 2). Table 2 shows that the protective equipment which most often prevented injuries in this sample was safety boots, followed by the safety helmet and leg protectors.

Nearly $70 \%$ of the respondents reported that the chain saw was under control when the near-accident occurred. Forty-three percent of the workers who had one near-accident situation lost their balance just prior to the near-accident.

The chain of the saw was stopped by the safety padding of the protective equipment in nearly every other nearaccident involving chain saws. The chain was blocked by padding material in every fifth situation. In $10 \%$ of the near-accidents, the chain perforated the protective equipment. In every fourth such incident the chain only lightly touched the protector.

Almost $40 \%$ of the respondents stated that the chain saw was operating at nearly full revolutions when the chain touched the leg protectors, safety boots, or safety gloves. Every fourth person said that the chain saw was operating at full revolutions.

\section{Accidents}

The loggers' responses to the questionnaire also included accidents which led to injuries. That particular question was answered by 1,075 loggers who had been involved in 172 accidents which led to more than $3 \mathrm{~d}$ of absence due to injury in 1979. The average duration of absence from work in this sample was $21 \mathrm{~d}$. According to the inquiry, the accident rate for motor-manual logging was 180 accidents per 1,000 annual employees. The official accident statistics of the National Board of Labour Protection show that the general accident rate for forest work in Finland was 154 accidents per 1,000 annual employees in that particular year.

\section{Deficiencies of protectors}

The loggers also gave their own opinions on the need to develop and improve individual safety equipment. The two most important items in need of product development seem to be eye protectors and safety boots. The most serious disadvantages of the eye protectors are poor visibility; steaming up, especially in the winter; glare; and their tendency to collect dirt and water.

\section{Conclusion}

The majority of the respondents claimed that loggers work more carefully if personal protectors are temporarily out of use. Thus it seems that work behavior becomes more careless when protectors are used. This view is supported by the fact that near-accident situations were very numerous among the respondents in comparison to the number of injurious accidents. On the other hand the respondents may have reported instances so small that they would not have led to injury without a protector. The method used to collect the data may not be completely valid with 
respect to the clarification of the number of prevented cases, but nevertheless the study gives valuable information on the value of protectors in accidental situations.

An important component of the present study is the cost-benefit analysis of forestry workers' protective equipment.
The preliminary results of that analysis show that the use of personal protectors is very profitable for employers and for society as a whole. The results also indicate that personal protectors play an important role in preventing and alleviating accidents in forest work. 